\title{
"Sometimes I feel like a pharmacist": identity and medication use among adolescents with juvenile arthritis
}

\author{
J. E. McDonagh ${ }^{*}$, K. L. Shaw², J. Prescott ${ }^{3}$, F. J. Smith ${ }^{4}$, R. Roberts ${ }^{5}$ and N. J. Gray ${ }^{6}$
}

\begin{abstract}
Background: Taking medicines as intended is difficult for everybody, but young people going through adolescence have greater problems than adults and younger children. One of the most important things that happen during the teenage years is the development of individual identities, which might not remain constant during this time and can be affected deeply by the diagnosis of a long-term condition. The aim of this study was to examine the relationships between identity and medication use among young people with juvenile arthritis.

Methods: A prospective qualitative study was undertaken to collect private online 'blog' style data from young people (aged 11-19 years) with juvenile arthritis, and their parents, to examine their views about their condition, identity, medication and use of health services. Participants were identified from a large paediatric hospital in the UK.

Results: Young people ( $n=21)$ with a median age 14 years (range 11-17 years) posted a median (range) of 8 (1-36) blogs and parents $(n=6)$ posted $4(1-12)$ blogs. Young people gave a strong sense of both private and public identity that was intertwined with their arthritis and treatment. It was evident that young people's self-care was intrinsically linked to their attempts to maintain a sense of individually and socially constructed definitions of normality. The act of taking medication, and the consequences (positive or negative) of that act, had an impact both personally and socially. Conclusions: Young people with juvenile arthritis reflect on their medication as a factor affecting their perception of themselves. Acknowledging the roles of both personal and social identity will be important in any strategies to support optimal medication use. This includes an understanding of the identity transformations that young people can experience and how decision-making may be affected by their attempts to retain pre-diagnosis identities and/or develop new social identities.
\end{abstract}

Keywords: Young people, Rheumatology, Identity, Medication, Qualitative

\section{Background}

Age and developmentally appropriate services, with particular reference to adolescents, have been reported nationally and internationally as a key mechanism to improve health outcomes for young people [1]. This has been recognised in rheumatology for over a decade [2]. Unfortunately, while there have been some encouraging advances in youth-friendly care [3], many young people remain inadequately prepared to manage their condition in adulthood $[4,5]$. Difficulties around medication are

\footnotetext{
*Correspondence: janet.mcdonagh@manchester.ac.uk

${ }^{1}$ Centre for Musculoskeletal Research, Stopford Building, University of

Manchester, Oxford Rd, Manchester, England M13 9PT, UK

Full list of author information is available at the end of the article
}

particularly evident, with suboptimal adherence reported in several studies [5-7]. The problems faced are many and complex, including negotiating the shift from parental- to self-management, and integrating medicine-taking within demanding daily routines [5-7]. Young people can also demonstrate a lack of basic knowledge about their medications $[5,8,9]$ and report significant concerns about side-effects and drug-dependency [5].

Helping young people to manage their medication and concerns is therefore a critical aspect of self-care. Not only is this congruent with adolescent development [10], but also a predictor of successful transition to adult care [11-13]. While there is evidence, however, that young people want to assume self-care responsibilities $[6,14,15]$, 
and that some rheumatology professionals encourage them to do so [11, 12], effective self-management training is not routinely provided $[16,17]$. The implications of this include adverse health outcomes, reduced quality of life and lost healthcare resources $[7,18]$.

Unfortunately, little is known about the optimal approach for self-management during adolescence. A recent synthesis of qualitative research shows that while medication management is important to young people, arthritis and its treatment can profoundly affect their sense of self [6]. Identity formation is one of the key developmental tasks of adolescence [10]. This includes both personal (or private) identity; "a definition and evaluation of oneself in terms of idiosyncratic personal attributes or one's relationships with specific people" and social (or public) identity; "a definition and evaluation of oneself in terms of shared attributes that define membership of the specific group one belongs to" [19]. However, while the experience of living with arthritis is well documented [6], there is scarce information about the relationship between identity and medication use. Understanding these relationships will be potentially helpful for health professionals when providing support to young people with long term conditions.

\section{Methods}

The aim of this study was therefore to examine the relationships between identity and medication use among young people with juvenile arthritis.

A prospective study (the 'Arthriting' project) [20, 21] was undertaken to collect private online 'blog' style data, employing principles of qualitative methodology from young people with arthritis, and their parents, to examine their views about their condition, identity, medication.

\section{Participants and setting}

Young people and their parents were identified from the rheumatology database in a large UK paediatric hospital. Eligibility criteria for young people required that they had confirmed juvenile arthritis, were aged 11-19 years, and had no cognitive impairment that would prevent their ability to provide data. Diagnoses of Juvenile arthritis included juvenile idiopathic arthritis as defined by ILAR criteria [22] in addition to other inflammatory arthritides prevalent during adolescence eg lupus or inflammatory bowel disease associated arthritis.

\section{Procedure}

A detailed description of the methodology of this study was already been published [ref]. In summary, young people (and their parents) were invited to participate during routine clinics $(n=70)$ and by letter $(n=107)$. Consenting participants were given an information pack about the 'Arthriting' website and a personal login code.
To maximise relevance and uptake, development of the website was undertaken in partnership with young people's user groups and included stringent security processes to ensure data protection and participant safety (e.g. password protected logins, secure firewalls, regular moderation). The website was also functional on Smartphones, recognising that many young people (and parents) access the Internet this way. Once registered, participants were asked to choose a nickname and password for future logins. Once logged in, participants were asked to choose from a number of blog categories [21] and enter their thoughts. This list had been generated by the research team to give young people ideas for the topics and types of messages that they might post (eg, thoughts about identity, the arthritis condition, medication, and the use of health services). These "blog categories" were developed and refined in discussion with the young people. They were also able to add an emoticon to reflect their mood at that time. The choice of categories, frequency of access and lengths of engagement was determined by participants, who could also edit blogs at any time during the 2-month active period. On completion of the 2-month period, participants who contributed at least one blog were sent a thank you letter and a $£ 50$ online shopping voucher.

\section{Analysis}

Blog entries for each participant were uploaded into QSR NVivo 10 (2012) as separate files and tagged with their nickname, date of posting, and emoticon. With permission, basic (non-identifiable) demographic and relevant clinical data were also added (i.e. age; sex; ethnic group; age at diagnosis, and number of medications). The data were analysed thematically using a 'middle-order' approach [23] within a framework of 'directed content analysis' [24]. This involved rigorous procedures to enable themes and categories to be generated from the data through processes of induction (i.e. moving from the data towards generalizations, hypotheses, or theory). This approach was possible because the blog activity was designed to generate data in relation to specific research objectives and thus provided a clear source of categories with which to organise participants' responses, whilst allowing other themes to emerge. Data was analysed by six experienced researchers. Primary attention was directed at identifying broad categories of data, which were used to develop an agreed codebook. Researchers then worked in pairs and were assigned a third of blog entries to analyse. This involved independent specific line-by-line categorisation, followed by paired discussions to establish the level of agreement and resolve discordance. Whole group consensus on the coding was established during several teleconferences. 


\section{Results}

\section{Participant characteristics}

In total, 36 (20.3\%) young people and 6 parents consented to participate (Table 1$)$. Of these, $25(14.1 \%)$ registered to participate and $21(11.9 \%)$ completed at least one blog. Of those young people who blogged, median age at recruitment was 14 years, most were female $(n=17$, $81.0 \%$ ), white ( $n=17,81.0 \%)$, and had Juvenile Idiopathic Arthritis $(n=19,90.5 \%)$ with a median age at diagnosis of 2.5 years. The median number of medicines being taken was $2(1-6)$.

Young people posted a median of $8(1-36)$ blogs and parents posted a median of $4(1-12)$ blogs. The unedited blogs are presented here as written by the participants.

\section{Impact during adolescence of arthritis on personal identity}

It was evident that adolescence posed distinct challenges for young people and their parents (Table 2a); young people had a sense of what was 'normal' for them based on past experiences. This varied depending on their age at disease onset (Table 2b). Those with an early onset (during infancy and early childhood) described how arthritis was a 'normal' part of their self, and how medication use was a routine part of life. Those diagnosed in later childhood or adolescence, however, described diagnosis as a life-changing event. Both parents and young people frequently contrasted life before and after diagnosis, describing how arthritis had profoundly affected young people's views of the world and how they acted within it. The response of many young people was to try and retain as much of their pre-illness self as possible. Unfortunately, the success of this was variable, leaving

Table 1 Characteristics of young people who contributed at least one blog

\begin{tabular}{lll}
\hline Characteristic & Values & $\begin{array}{l}\text { Number of } \\
\text { participants }\end{array}$ \\
\hline Age at recruitment & $11-15$ & 18 \\
& $16-19$ & 3 \\
Gender & Female & 17 \\
& Male & 4 \\
Ethnic group & White & 17 \\
Age at diagnosis & Non-white & 4 \\
& $<11$ years & 13 \\
Time since diagnosis & $11+$ years & 8 \\
& 6-5 years & 8 \\
& $11+$ years & 4 \\
& Not known & 8 \\
Type of juvenile arthritis & Juvenile Idiopathic Arthritis JIA & 19 \\
& Other & 2 \\
\hline
\end{tabular}

some young people frustrated and disappointed. This was further compounded by the remitting/relapsing nature of arthritis and its treatment which could alter their 'usual' self on a temporary or episodic basis (Table 2c).

Young people strived to engage in behaviours that were defined as developmental ly and culturally normal. While this could be detrimental to their physical health (e.g. exacerbating symptoms), young people were very mindful of how they appeared to others and lack of participation was felt to have significant consequences for young people's sense of belonging (Table $2 \mathrm{~b}, \mathrm{c}$ ). Interestingly, some young people also described their arthritis and/or treatment as a positive force in their lives (Table $2 \mathrm{~d}$ ).

Commensurate with their increasing cognitive abilities, young people were beginning to consider their futures. However, forming and consolidating an identity that incorporated the future self could be extremely challenging, especially given the remitting/relapsing nature of arthritis (Table 2e).

\section{Medication, medicine management, and person identity} For some young people, medication affected their sense of self (Table 3a). The value of medication was intrinsically linked to its potential to protect or threaten the young person's self-identity. Thus, while some young people described their health regimens as onerous and unwelcome, they felt that the real and anticipated benefits outweighed the level of disruption (Table 3b). Many young people acknowledged their need for the medication, seeing it as important if they were to stay well and for longer term disease outcomes. Thus, young people were often faced with a paradox. Effective disease management could help them maintain a sense of self by minimising symptoms, the visibility of their condition and enabling them to participate in identity-confirming activities. Yet, at the same time, medication (and other aspects of treatment) were both a public and private reminder of their illness. Visible side-effects of medication, in particular, could disrupt a sense of self (Table 3c).

Young people were increasingly responsible for their medicine management, and while it was often seen as onerous, it could also be empowering (Table 3c). Young people described making different self-care choices to manage their social identities within the demands of different situations. Life within the family was rarely seen to threaten the young person's sense of normality, and thus young people and parents often worked constructively to negotiate and support greater independence in using medications. However supporting their child's developing autonomy was not always easy for the parents (Table 3d)

\section{Arthritis, medication use and public identity}

Although many young people were developing a personal identity that incorporated arthritis and/or its 
Table 2 Blog reflections upon arthritis and personal identity

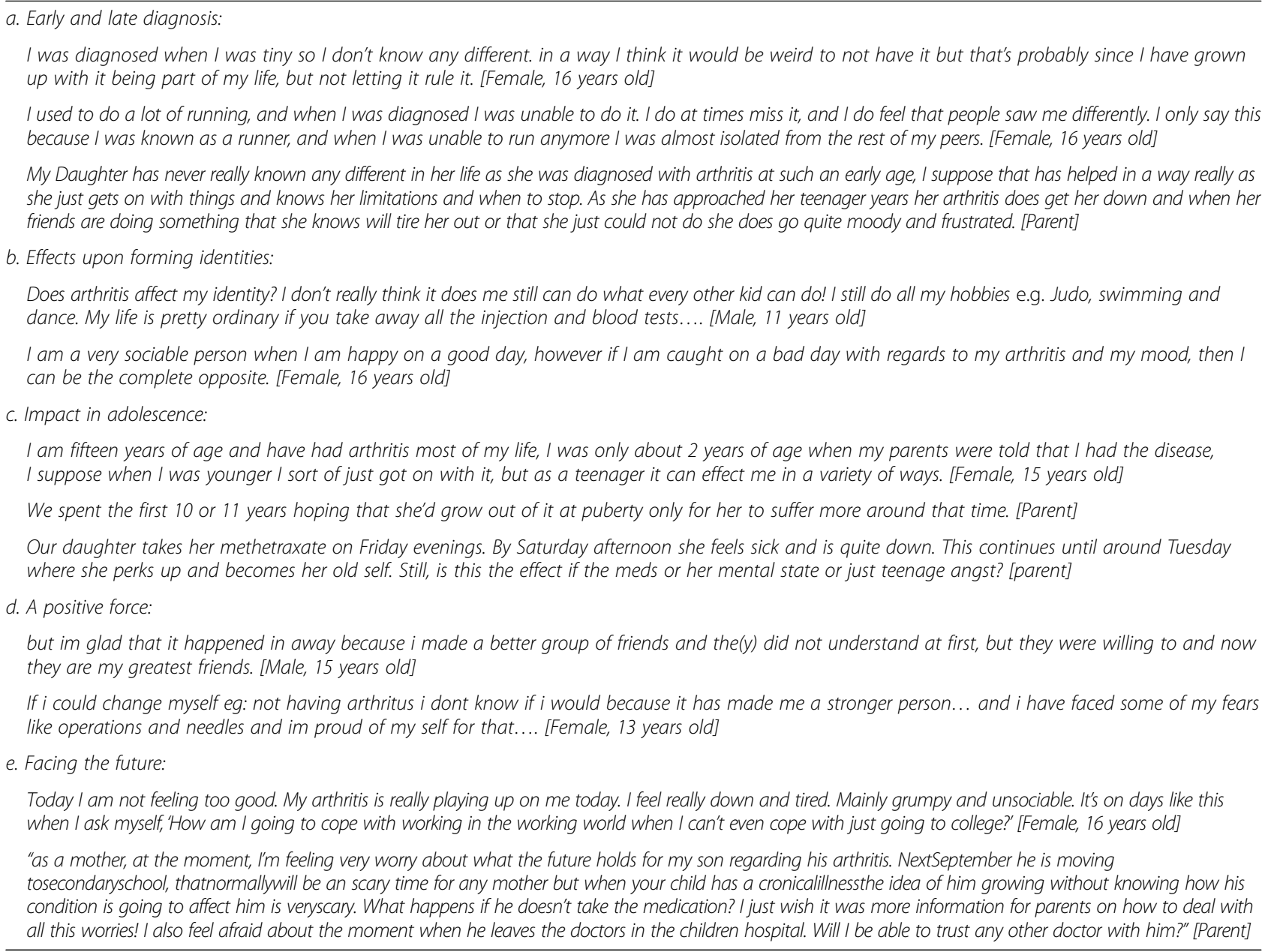

management, it was clear that young people also wanted to create and maintain a public identity that adhered to social definitions of normality. Some young people therefore described how arthritis and its treatments led to experiences of normality which differed significantly to those of others, particularly their peers. This was compounded by the limited representation of juvenile arthritis in society or public understanding (Table 4a). Disclosure, of any type, often meant that young people with arthritis needed to 'explain themselves' and this was often a source of frustration, especially when explanations were not fully accepted or understood.

A recurrent theme in the blogs was the need to minimise difference in order to form and maintain a positive social identity. A common strategy used by young people was to conceal or minimise the significance of their arthritis by reducing the visibility of their condition, including self-management activities, and limiting disclosure (Table 4b). Yet, paradoxically, invisibility was itself a problem because others did not always appreciate the impact of arthritis. Young people therefore have to make decisions about disclosure, balancing its potential benefits and risks.

Young people belonged to varied social groups and presented different images of themselves depending on the context (Table 4c). While arthritis could be highly disruptive in some social settings, it was perceived as less relevant in others. Young people therefore described making different self-care choices to manage their social identities within the demands of different situations. Close friends and romantic partners were often brought into the 'circle of trust'. These relationships appeared to support - rather than threaten - young people's social identity, given their defining features of reciprocal selfdisclosure, support and mutual interest.

\section{Discussion}

Young people gave a strong sense of both private and public identity that was intertwined with their arthritis and medication use. The overarching theme was one of 'normality' which echoes the findings of a recent review of qualitative studies that describe the experiences of 
Table 3 Blog reflections upon medication (including medication management) and personal identity

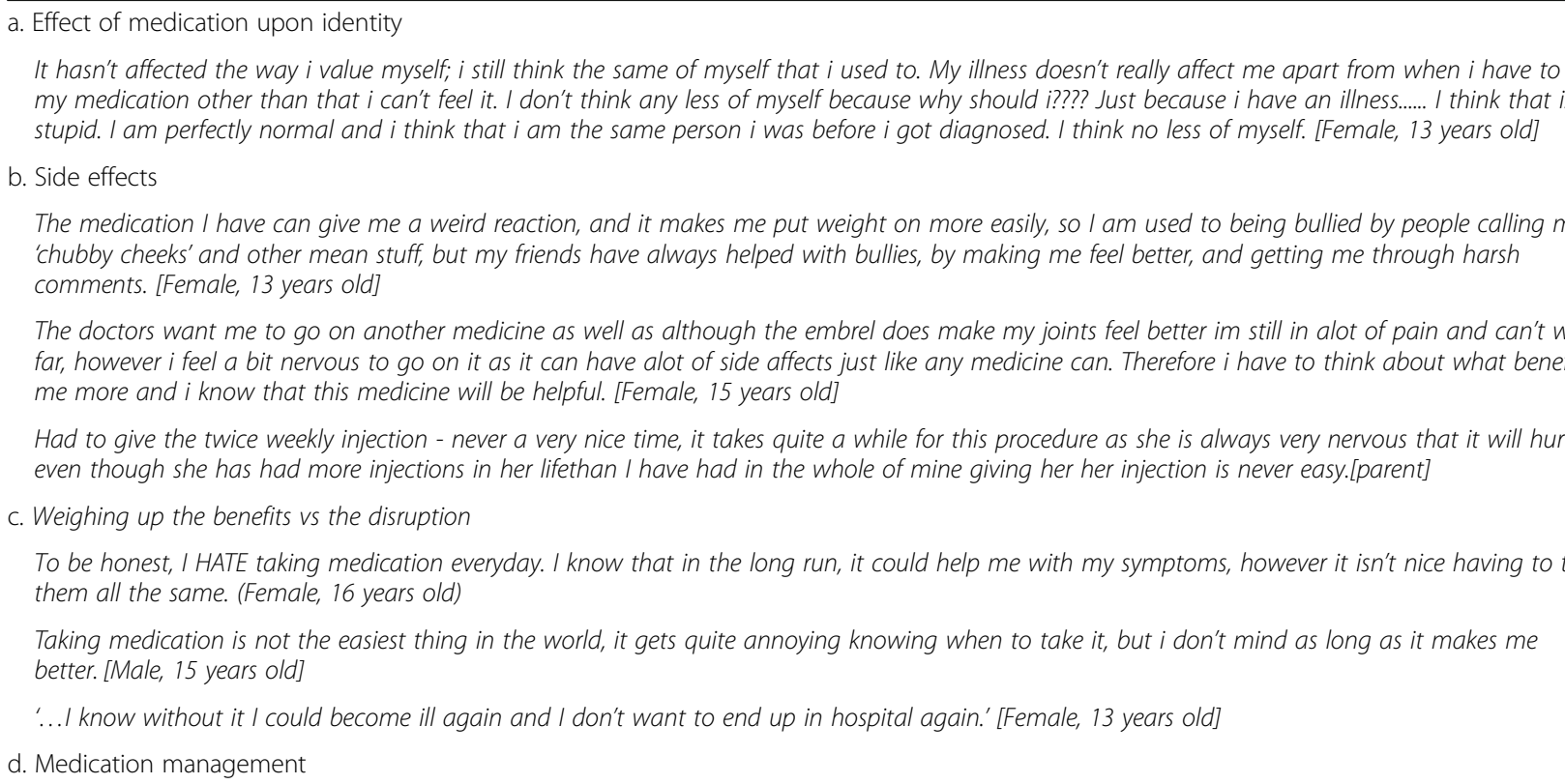

To be honest, there aren't that many positives when it comes to taking medication. I know that I have said this many times, but I feel that the main positive that has come from taking medication is having a sense of independence. I absolutely hate taking medication, but I cannot deny that it has given me an insight of taking responsibility for things. (Female, 16 years old)

I kind of enjoy being in charge of my medication because sometimes I feel like a pharmacist??? [Female, 13 years old]

Now I'm kinda like an expert on medication i know all the doses and names of my medications. [Female, 13 years old]

Do i get enough help from my friends and family??? Yes i do everyone helps me in every way they can although i don't need a lot of help. My friends don't really need to help however they do sometimes ask have you had your medication? I am in charge of my medication therefore i am responsible for it. My mother helps by getting my prescription and collecting the medication from the chemist as i am not aloud because $i$ am to young. [Female, 13 years old]

I feel really pleased that my daughter has taken full responsibility for taking her medication, there have only been a few times when she has forgotten to take it [parent\}

The thought of our son been in control of the medication is a very frightening thought. As parents we know that the moment will have to arrive so he becomes responsible of his well being and independent but never the less still a worry because when you are in control your mind is at rest that you are doing it right but when you have to trustsome else with the medication becomes another thing for your head to worry about!!! [parent]

children and adolescents living with juvenile idiopathic arthritis [6, 25], as well as those observed in other conditions (e.g. liver transplantation [26] haemoglobinopathies [27], Cystic Fibrosis [28]). However, by focusing on identity and medication use, this study adds to the current knowledge base by revealing how the desire for normality influences medication use. Specifically, it shows that young people judge the value of their medicines against their potential to support or disrupt their perceptions of what is normal for them, and their attempts to 'fit in' with socially constructed views of normality. From this stance, medicine management therefore needs to start with an understanding of how young people see themselves, how they think others see them, and their goals and aspirations.

The relationship between arthritis, treatment and identity appeared particularly complex for young people diagnosed in later childhood and adolescence, who described their attempts to reconcile life before and after onset. Parallels can be drawn with the sociological concepts of 'biographical disruption' [29] and 'loss of self' [30] which describe how chronic conditions can alter the 'taken-forgranted' features of life and force individuals to reappraise the meaning of their lives. Although these concepts derive from adult studies, the responses of many young people were comparable, in that they tried to preserve their preillness identity (sometimes by concealing their condition and treatment), with some also showing evidence of developing an altered identity that incorporated arthritis as an accepted (and sometimes positive) component of life. Moreover, Grinyer [31], in her work with young people with cancer, suggests that the potential for biographical disruption is exacerbated in adolescents, given that they are at a transitional stage of life where identity is particularly fragile and developmental goals include increased independence. Others additionally suggest that the development of identity is further complicated at this stage of life by the 'inherent tensions' between the concept of youth (typically portrayed as a time of health, beauty, strength etc.) and illness/impairment [32, 33]. This is not 
Table 4 Blog reflections upon arthritis, medication and public identity

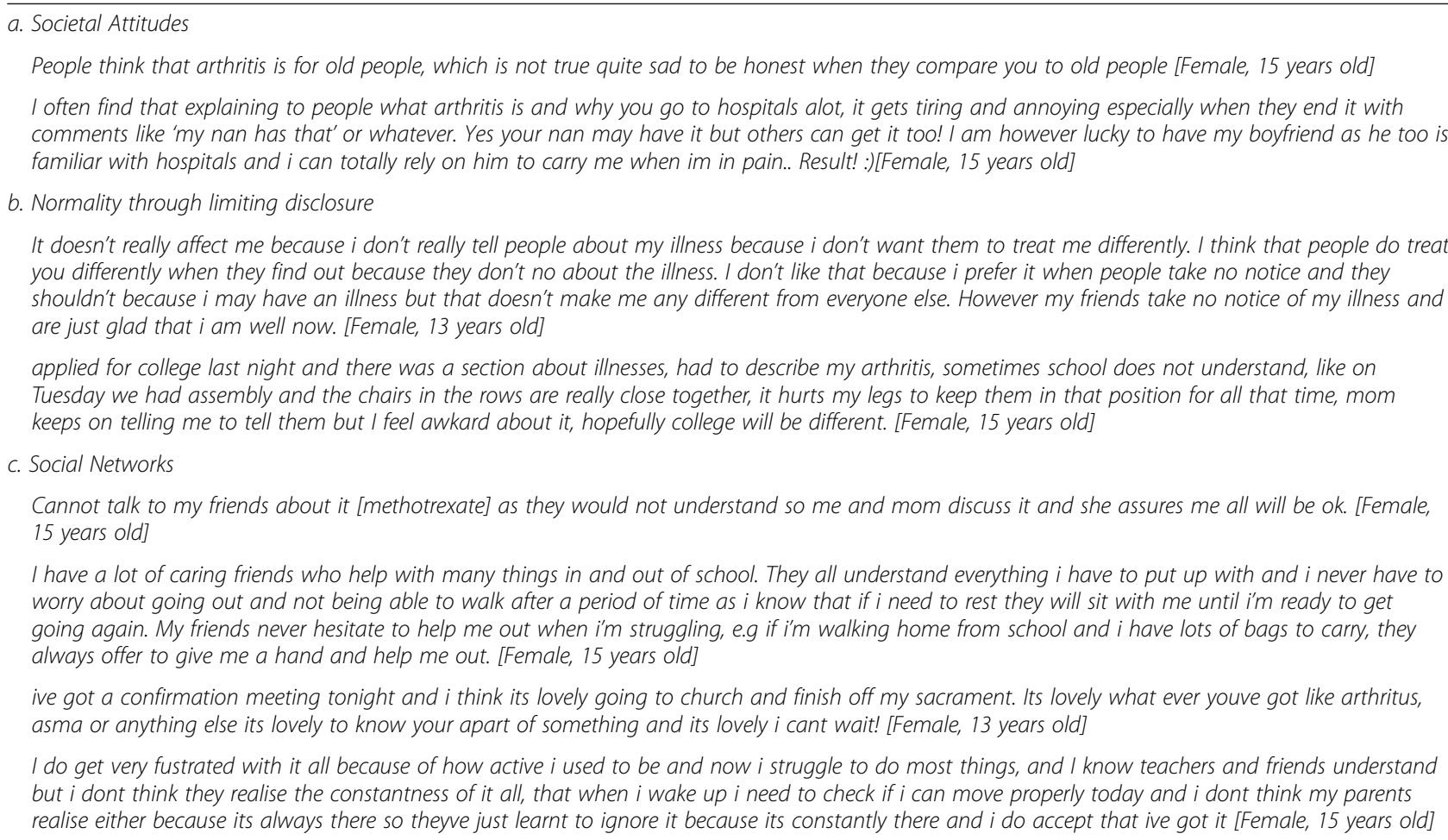

to say that identity formation is necessarily easier for young people diagnosed in early childhood. Regardless of onset age, adolescence raised additional challenges for young people, including consideration of their place in the world and the future. Thus, compared to adults, whose illness requires them to re-construct an already established identity, the young people in this study were presented with the arguably more complex challenge of creating and consolidating an identity in the context of a condition that may fluctuate, have uncertain outcomes and is typically represented as a disease of older adulthood. As such, the findings lend support to the conclusions of Williams et al. [28] who, in the context of cystic fibrosis, suggest that the task faced by young people is to continually revise their biographies "in anticipation of future illness trajectory and life course” (p.1443).

Effective medicine management strategies are likely to require a meaningful exploration of young people's support needs across a range of social contexts. Newbould et al. [34] caution against judging a patient's potential to manage their condition based on clinic behaviour. They found that while young people with asthma and diabetes played a considerable role in managing their medicines at home, they often adopted a passive role in clinic consultations. It is important, therefore, to provide opportunities for young people to make care plans that acknowledge their desires for self- and socially- referenced normality and which include reference to their goals and aspirations. Given the loss of self that many young people experience, it will also be important to highlight the gains that can be experienced through self-care activities, as described in this study (i.e. sense of personal growth and mastery). Young people may also feel more motivated if they have a greater understanding of how self-care activities can facilitate participation in their valued activities, and how symptoms and side-effects that threaten identity could be minimized or managed. This is important as the perceived burden of medication has been shown to predict impaired health related quality of life in young people with JIA [35].

There remains much to be done to increase the social representation of arthritis in young people. As in other studies [6, 36], young people and parents were often concerned about the lack of social understanding, particularly at school and work. This is of relevance in view of the reported concerns regarding vocational outcomes for young people with long term health conditions [37], and the increasing interest in rheumatology research in this area [38, 39].

The findings presented here underscore the need to provide young people with permissive environments in which to explore medication use in the context of their everyday lives. This reflects the central tenets of selfcategorisation theory [40] that regards young people as having a variety of social identities which become salient in different contexts. In this context, medication use 
Table 5 Implications for practice and further study

- Provision of permissive environments in which to explore medication use with young people in the context of their everyday lives.

- Effective medicine management strategies which explore young people's support needs across a range of social contexts

- Provision of opportunities for young people to make care plans that acknowledge their desires for self- and socially- referenced normality and which include reference to their goals and aspirations.

- Enhance young people's understanding of how self-care activities can facilitate participation in their valued activities and how symptoms and side-effects that threaten identity could be minimised or managed.

- Enhance young people's understanding of how symptoms and side-effects that threaten identity could be minimised or managed.

- Skills training for young people which will enable them to negotiate the social situations that they are likely to encounter eg opportunities to develop and practice positive disclosure skills

(and other aspects of self-care, including disclosure) is seen as a choice, but one that is subject to the context of the specific social situation. Thus, effective medicine management strategies are likely to require a meaningful exploration of young people's support needs across a range of social contexts. Interviewing tools such as HEADSSSS are likely to support such strategies [41, 42] although such psychosocial screening is not yet standard practice [17, 43]. Implications for clinical practice are detailed in Table 5. This data has since informed a further study of pharmacists' perceived role in the care of young people with rheumatic disease using JIA as an exemplar disease [44], the paper of which has been submitted to the Journal of adolescent health and is in the revision stage. As a result of the latter study, a trial of a pharmacy-led intervention to improve medicine management skills, patient reported outcomes and reduce healthcare resource use through improved engagement in health care is currently in the development phase.

\section{Limitations}

The novel way of engaging with young people and parents in this study has resulted in rich in-depth data about the relationships between arthritis, identity and medication use. However, several caveats should be borne in mind when interpreting the findings. Firstly, the response rate was low and the sample was selfselected, possibly reflecting those who felt competent with online activities and had reasonable literacy skill. The requirement for access to a smartphone or computer may also have excluded young people of lower socioeconomic status. Responses may have been improved if we had offered a choice of data collection methods (e.g. interviews, focus groups) and may have supported wider participation, including those with no/limited confidential access to the Internet. Given the relatively small number of participants, there are limits to the inferences that can be made. This is discussed further in the methodology paper [22]. However, there were a number of consistent and identifiable themes and while not all participants gave evidence of every theme, common patterns of meaning were discerned and have been presented. A wider age range and longer follow-up may also have provided greater insight into how identity changes over time, especially given that much identity development also occurs in late adolescence and sometimes not until young adulthood [45].

The low response rate is in itself of interest in view of the increasing interest in the use of ehealth and mhealth interventions with this age group in health care [46]. Young people were however involved from the outset including in the design of the blogging site to try and enhance both recruitment and retention. Further study of the potential of such technologies in both research and clinical settings is awaited.

\section{Conclusion}

The use of a novel methodology to empower young people to express their feelings about living with juvenile arthritis has provided a naturalistic description of their concerns and triumphs. Young people with juvenile arthritis reflect on their medication as a factor affecting their perception of themselves. The physical act of taking medication, and the consequences (positive or negative) of that act, have an impact both personally and socially. Family and friends may reinforce these associations with well-intentioned reminders. The exploration of the impact of arthritis and medicine-taking on identity, and the young person's feeling of normality, may offer healthcare providers further ways to achieve concordance and thus to optimise adherence.

\section{Acknowledgements}

The authors would like to thank the young people and parents who took part in the Arthriting study and who advised the team during the development of the website. We would like to acknowledge Marie McGee, the hospital adolescent rheumatology transition co-ordinator, for her support with the young people's advisory group. We would also like to thank Terry Abbas and Ambinet Software for website creation. Rachel Stephenson was the research assistant to the project; she and other members of the adolescent rheumatology team at Birmingham Children's Hospital NHS Trust helped us to recruit participants from clinic. We would also like to thank the other members of the wider study team - Kevin Harvey (Sociolinguistics, University of Nottingham), David Terry (Pharmacy, Aston) and Kate Fleck (Arthritis Care, Belfast), and the PRUK Advisory Group. Karen Shaw is funded by the NIHR CLAHRC West Midlands initiative. This paper presents independent research and the views expressed are those of the author(s) and not necessarily those of the NHS, the NIHR or the Department of Health. 


\section{Funding}

This research was funded by Pharmacy Research UK, an independent charity.

\section{Availability of data and material}

The full data set ie the complete blogs written by the young people that support the findings of this study are not publicly available due to the restrictions of the ethics approval originally obtained.

\section{Authors' contributions}

JMcD and NJ wrote the successful application for funding and were co-principal investigators of the study. KLS and JMCD co-led on the writing of this manuscript and all authors read and approved the final version. NJ was the research associate who led the development of and moderated the website with support from $J M C D$. NJ led the analysis of the data which involved all authors. All authors read and approved the final manuscript.

\section{Competing interests}

The authors declare that they have no competing interests.

\section{Consent for publication}

No identifiable data is included in the paper.

\section{Ethics approval and consent to participate}

The study was approved by the NRES Coventry and Warwickshire Research Ethics Committee (ref: 12/WM/0184).

\section{Author details}

${ }^{1}$ Centre for Musculoskeletal Research, Stopford Building, University of Manchester, Oxford Rd, Manchester, England M13 9PT, UK. ${ }^{2}$ NIHR CLAHRC West Midlands, University of Birmingham, Birmingham, UK. ${ }^{3}$ School of Education and Psychology, University of Bolton, Bolton, England, UK. ${ }^{4} \mathrm{UCL}$ School of Pharmacy, London, England, UK. ${ }^{5}$ Pharmacy Research UK, London, England, UK. ${ }^{6}$ Green Line Consulting Limited, Manchester, England, UK.

\section{Received: 7 July 2016}

\section{Published online: 19 October 2016}

\section{References}

1. Patton GC, Sawyer SM, Santelli JS, Ross DA, Afifi R, Allen NB, Arora M, Azzopardi P, Baldwin W, Bonell C, Kakuma R, Kennedy E, Mahon J, McGovern T, Mokdad AH, Patel V, Petroni S, Reavley N, Taiwo K, Waldfogel J, Wickremarathne D, Barroso C, Bhutta Z, Fatusi AO, Mattoo A, Diers J, Fang J, Ferguson J, Ssewamala F, Viner RM. Our future: a Lancet commission on adolescent health and wellbeing. Lancet. 2016:387(10036):2423-78.

2. McDonagh JE, Foster $\mathrm{H}$, Hall MA, Chamberlain MA on behalf of the BPRG. Audit of rheumatology services for adolescents and young adults in the UK. Rheumatology. 2000;39:596-602. 602.

3. Castrejón I. Transitional Care Programs for Patients with Rheumatic Diseases: Review of the Literature. Reumatol Clin. 2012;8(1):20-6.

4. McDonagh JE, Shaw KL. Adolescent Rheumatology Transition Care in the UK. Pediatr Ann. 2012;41(5):e8-e15.

5. Lawson EF, Hersh AO, Applebaum MA, Yelin EH, Okumura MJ, von Scheven E. Self-management skills in adolescents with chronic rheumatic disease: A cross-sectional survey. Pediatr Rheumatol Online J. 2011;9:35.

6. Tong A, Jones J, Craig JC, Singh-Grewal D. Children's experiences of living with juvenile idiopathic arthritis: a thematic synthesis of qualitative studies. Arthritis Care Res. 2012:64:1392-404.

7. Dobbels F, Shaw KL. Adherence and chronic rheumatic diseases. In McDonagh JE, White PH (Eds). Adolescent Rheumatology. Marcel Dekker, Inc. (2008)

8. Shaw KL, Southwood TR, McDonagh JE. What's in a name? Disease knowledge in juvenile idiopathic arthritis (JIA). Rheumatology. 2004;43 suppl 2:275

9. McDonagh JE, Southwood TR, Shaw KL. British Society of Paediatric and Adolescent Rheumatology. The impact of a coordinated transitional care programme on adolescents with juvenile idiopathic arthritis. Rheumatology. 2007;46(1):161-8.

10. Christie D, Viner R. Adolescent development. BMJ. 2005:330:301-4.

11. Hilderson D, Moons P, Westhovens R, Wouters C. Attitudes of rheumatology practitioners toward transition and transfer from pediatric to adult healthcare. Rheumatol Int. 2012;32:3887-96.
12. van Staa A, Jedeloo S, van der Stege H, On Your Own Feet Research Group. "What we want": chronically ill adolescents' preferences and priorities for improving health care. Patient Prefer Adherence. 2011;5:291-305.

13. Crowley R, Wolfe I, Lock K, McKee M. Improving the transition between paediatric and adult healthcare: a systematic review. Arch Dis Child. 2011;96:548-53.

14. Ammerlaan JW, Scholtus LW, Bijlsma HJWJ, Prakken BJ, Kruize AA. An urge for change: Transitional care for young adults with juvenile idiopathic arthritis. Patient Educ Couns. 2013:92:127-9.

15. Stinson JN, Toomey PC, Stevens BJ, Kagan S, Duffy CM, Huber A, Malleson P, McGrath PJ, Yeung RS, Feldman BM. Asking the experts: exploring the selfmanagement needs of adolescents with arthritis. Arthritis Rheum. 2008;59:65-72

16. Scal P, Horvath K, Garwick A. Preparing for adulthood: health care transition counseling for youth with arthritis. Arthritis Rheum. 2009:61:52-7.

17. Robertson LP, McDonagh JE, Southwood TR, Shaw KL. British Society of Paediatric and Adolescent Rheumatology. Growing up and moving on. A multicentre UK audit of the transfer of adolescents with Juvenile Idiopathic Arthritis JIA from paediatric to adult centred care. Ann Rheum Dis. 2006;65:74-80

18. Sabate E. Adherence to long-term therapies: Evidence for action. Switzerland: World Health Organization; 2003.

19. Hogg, M. A., \&c Tindale, R. S. (2005). Social identity, influence, and communication in small groups. In J. Harwood \& H. Giles (eds), Intergroup communication: Multiple Perspectives (pp141-164), New York: Peter Lang.

20. Gray NJ, McDonagh JE, Harvey K, Prescott J, Shaw KL, Smith FJ, Stephenson R, Terry D, Fleck K, Roberts R. Arthriting: Exploring the relationship between identity and medicines use, and to identify the contribution of medicines and pharmacy services, for the care of young people with arthritis. Final report. Pharmacy Research UK, London; December 2013. http://www.pharmacyresearchuk.org/waterway/ wp-content/uploads/2013/07/Arthriting-full-report-final-formatted-12dec13.pdf last Accessed 2 Sept 2016)

21. Prescott J, Gray NJ, Smith FJ, McDonagh JE. Blogging as a viable research methodology for young people with arthritis: A qualitative study. J Med Internet Res. 2015;17(3):e61. doi:10.2196/jmir.3608.

22. Petty RE, Southwood TR, Manners P, Baum J, Glass DN, Goldenberg J, He X, Maldonado-Cocco J, Orozco-Alcala J, Prieur AM, Suarez-Almazor ME, Woo P; International League of Associations for Rheumatology. International League of Associations for rheumatology classification of juvenile idiopathic arthritis: 2nd revision, Edmonton, 2001 J Rheumatol. 2004 31(2):390-2.

23. Becker H, Geer B. Participant observation: the analysis of qualitative field data. In: Burgess R, editor. Field research: a sourcebook and field manual. ondon: Allen and Unwin; 1982. p. 53-61.

24. Hsieh H-F, Shannon SE. Three approaches to content analysis. Qual Health Res. 2005;15:1277-88.

25. Hart RI, McDonagh JE, Thompson B, Foster HE, Kay L, Myers A, Rapley T. "Being'as normal as possible': How young people (aged 16-25 years) evaluate the risks and benefits of treatment for inflammatory arthritis. Arthritis Care Res. 2016:68(9):1288-94.

26. Wright J, Elwell L, McDonagh JE, Kelly DA, Wray J. 'It's hard but you've just gotta get on with it' - The experiences of growing-up with a liver transplant. Psychol Health. 2015;2:1-29.

27. Atkin K, Ahmad WIU. Living a "normal" life: Young people coping with thalassaemia major or sickle cell disorder. Soc Sci Med. 2001;53:615-26.

28. Williams B, Corlett J, Dowell JS, Coyle J, Mukhopadhyay S. I've never not had it so I don't really know what it's like not to: nondifference and biographical disruption among children and young people with cystic fibrosis. Qual Health Res. 2009:19:1443-55.

29. Bury MR. Chronic illness as a biographical disruption. Sociol Health IIIn. 1982;4:167-82

30. Charmaz K. Loss of self: a fundamental form of suffering in the chronically ill. Sociol Health IIIn. 1983:5:168-95.

31. Grinyer A. The biographical impact of teenage and adolescent cancer Chronic Illn. 2007:3:265-77.

32. Hughes B, Russell R, Paterson K. Nothing to be had 'off the peg': consumption, identity and the immobilization of young disabled people. Disability Soc. 2005;20:3-17.

33. Buckingham, D. The Impact of the Commercial World on Children's Wellbeing. Report of an Independent Assessment. For the Department for Children, Schools and Families and the Department for Culture, Media and Sport. DCSF Publications. 2009 
34. Newbould J, Smith F, Francis S. I'm fine doing it on my own': partnerships between young people and their parents in the management of medication for asthma and diabetes. J Child Health Care. 2008;12:116-28.

35. Haverman L, Grootenhuis MA, van den Berg JM, van Veenendaal M, Dolman KM, Swart JF, Kuijpers TW, van Rossum MA. Predictors of health-related quality of life in children and adolescents with juvenile idiopathic arthritis: results from a Web-based survey. Arthritis Care Res. 2012;64:694-703.

36. Shaw KL, Hackett J, Southwood TR, McDonagh JE. The Prevocational and Early employment needs of adolescents with juvenile idiopathic arthritis: the adolescent perspective. Br J Occup Ther. 2006;69(3):98-105.

37. Hale DR, Bevilacqua L, Viner RM. Adolescent Health and Adult Education and Employment: A Systematic Review. Pediatrics. 2015;136(1):128-40.

38. Jetha $A$. The impact of arthritis on the early employment experiences of young adults: A literature review. Disability Health J. 2015;8:317-24.

39. Jetha A, Badley E, Beaton D, Fortin PR, Shiff NJ, Gignac MA. Unpacking early work experiences of young adults with rheumatic disease: an examination of absenteeism, job disruptions and productivity loss. Arthritis Care Res. 2015;67(9):1246-54.

40. Turner JC, Onorato RS. Social identity, personality, and the self-concept: A self-categorization Perspective. In: Tyler TR, Kramer RM, John OP, editors. The psychology of the social self. Mahwah: Lawrence Erlbaum Associates; 1999. p. 11-46.

41. Goldenring JM, Rosen DS. Getting into adolescent heads: an essential update. Contemp Pediatr. 2004;21:64-90.

42. Wells CK, McMorris BJ, Horvath K, Garwick AW, Scal PB. Youth report of healthcare transition counseling and autonomy support from their rheumatologist. Pediatr Rheumatol Online J. 2012;10(1):36. doi:10.1186/15460096-10-36.

43. Boisen KA, Hertz PG, Blix C, Teilmann G. Is HEADS in our heads? Health risk behavior is not routinely discussed with young people with chronic conditions. Int J Adolesc Med Health. 2015 Sep;11 [Epub ahead of print]

44. Gray NJ, McDonagh JE, Barker C, Burton J, Prescott J, Shaw KL, Smith FJ, Terry D. Exploring the perceived and potential medicines optimisation role of pharmacy for young people with long-term conditions, through the case study of juvenile arthritis. Final report. London: Pharmacy Research UK; 2016. http://www.pharmacyresearchuk.org/our-research/our-projects/potentialmedicines-optimisation-role-pharmacy-young-people-long-term-conditions/. Accessed 12 Oct 2016

45. Arnett JJ. Emerging Adulthood: The Winding Road From the Late Teens Though the Twenties. New York: Oxford University Press=; 2004

46. Majeed-Ariss R, Baildam E, Campbell M, Chieng A, Fallon D, Hall A, McDonagh JE, Stones SR, Thomson W, Swallow V. Apps and Adolescents: A Systematic Review of Adolescents' Use of Mobile Phone and Tablet Apps That Support Personal Management of Their Chronic or Long-Term Physical Conditions. J Med Internet Res. 2015;17(12):e287.

\section{Submit your next manuscript to BioMed Central and we will help you at every step:}

- We accept pre-submission inquiries

- Our selector tool helps you to find the most relevant journal

- We provide round the clock customer support

- Convenient online submission

- Thorough peer review

- Inclusion in PubMed and all major indexing services

- Maximum visibility for your research

Submit your manuscript at www.biomedcentral.com/submit

Biomed Central 